Journal of Forecasting

J. Forecast. 29, 517-522 (2010)

Published online 1 September 2009 in Wiley InterScience

(www.interscience.wiley.com) DOI: 10.1002/for.1136

\title{
Spreads versus Professional Forecasters as Predictors of Future Output Change
}

\author{
KEVIN ARETZ ${ }^{*}$ AND DAVID A. PEEL ${ }^{2}$ \\ ${ }^{1}$ Department of Accounting and Finance, Lancaster University, Lancaster, UK \\ ${ }^{2}$ Department of Economics, Lancaster University, Lancaster, UK
}

\begin{abstract}
We examine whether real output forecasts obtained from the Survey of Professional Forecasters efficiently embody information in the term structure spread. To this end, we employ revised data as well as real-time vintage data, and we also allow for the possible impact of asymmetric loss functions. Assuming quadratic loss, our results suggest that the term structure spread does contain information useful for forecasting not reflected in the survey forecasts, at least over the longest forecast horizon. However, if we allow agents' loss functions to become more negatively skewed with the forecast horizon, then we cannot reject the rationality of the survey forecasts. Copyright (C) 2009 John Wiley \& Sons, Ltd.
\end{abstract}

KEY WORDS real GDP growth; Survey of Professional Forecasters; term structure

\section{INTRODUCTION}

Economists have long suggested that the current term spread, i.e. the difference between a long and a short interest rate, is related to future changes in real output. Bordo and Haubrich (2008) point out that Mitchell, as early as 1913, noted different patterns in long and short rates, while Kessel (1965) more explicitly described how the term structure varied with the business cycle. Subsequently, numerous authors have reported significant predictive content of the term spread for future real output for different economies and time periods (see, for example, Estrella and Hardouvelis, 1991; Plosser and Rouwenhorst, 1994; Estrella and Mishkin, 1998; Mody and Taylor, 2003). This empirical evidence is consistent with a variety of structural models from which a reduced-form relationship between the spread and future output change can be obtained (see, for example, Estrella, 1998).

Given the predictive content of term spreads, their wide accessibility and the knowledge of this relationship in economic and forecasting circles, it is perhaps interesting to analyse whether the forecasts of professional forecasters embody efficiently the information in term spreads related to future output changes. This is the purpose of this letter. We employ the consensus (mean) forecasts of future output changes of the Survey of Professional Forecasters, which are available at a quarterly

\footnotetext{
* Correspondence to: Kevin Aretz, Department of Accounting and Finance, Lancaster University, Lancaster LA1 4YX, UK. E-mail: k.aretz@lancaster.ac.uk

Copyright (C) 2009 John Wiley \& Sons, Ltd.
} 
frequency and whose respondents include many high-profile groups (see Croushore, 1993, for comprehensive details of the survey). The results of the survey are often reported in major newspapers, including the Wall Street Journal, and on financial newswires. The consensus forecast is the usual focus of press reports and, a priori, the likely input into the forecast of users. We initially employ standard tests in which realized growth is regressed on the consensus forecast and the lagged term spread. These tests assume that agents' preferences can be described with quadratic loss functions. As Elliott et al. (2005) show, they are not robust to small deviations from symmetric loss. To avoid this problem, we also use a new methodology proposed by the former authors. As our outcomes could be sensitive to employing ex post as opposed to real-time data (see Stark and Croushore, 2002), we examine our hypothesis with both datasets.

\section{DATA}

We obtain the mean consensus forecast of seasonally adjusted real output for the current and the four subsequent quarters from the Survey of Professional Forecasters. In the survey, real economic output is measured through the real gross national product (GNP) before 1992 and through the real gross domestic product (GDP) afterwards. We download the revised time series of actual GDP or GNP from the Bureau of Economic Analysis. As the usage of revised data could distort our inferences, we also employ time series of real-time GDP or GNP observed $q$ quarters after the survey has been conducted, where $q$ is the forecast horizon in quarters. ${ }^{1}$ We compute annualized actual or predicted real output growth through

$$
\text { Real output growth }{ }_{t, t+q}=\left[\left(\frac{\text { Real GD }(\mathrm{N}) \mathrm{P}_{t+q}}{\text { Real GD }(\mathrm{N}) \mathrm{P}_{t}}\right)^{\frac{4}{q}}-1\right] * 100
$$

where $t$ is the forecast production date. The term structure spread is defined as the difference between a 10-year US government bond yield and a 3-month US Treasury bill yield. Yield data can be obtained from the Board of Governors of the Federal Reserve System.

\section{EMPIRICAL FINDINGS}

In Table I, we show the outcomes of OLS regressions of future realized output growth onto subsets of a constant, the mean consensus forecast from the Survey of Professional Forecasters and the 1month lagged term structure spread. We lag the term structure spread by 1-month to ensure that forecasters had access to this information. Bold numbers are parameter estimates, while numbers in square brackets are OLS $t$-statistics. The numbers in curly brackets are the $90 \%$ and $95 \%$ critical values computed from the stationary bootstrap of Politis and Romano (1994), which allows for weakly dependent observations over time.

While the real-time dataset and the revised dataset can lead to minor differences, main conclusions are similar across the two datasets. As a result, we only report the outcomes obtained from the

\footnotetext{
${ }^{1}$ The survey data and the real-time GNP/GDP vintages can be obtained from the Federal Reserve Bank of Philadelphia.
} 


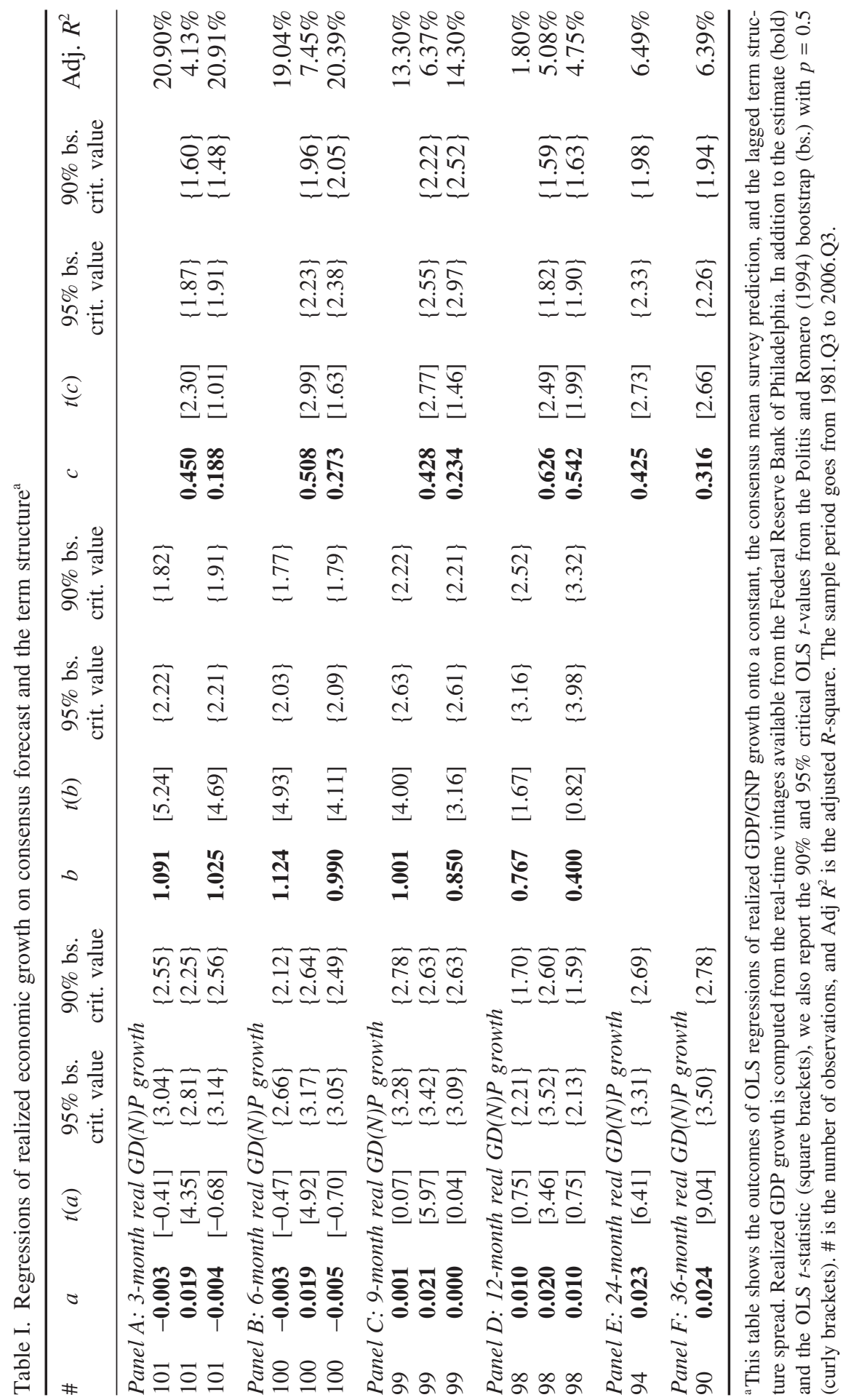


real-time dataset in the tables. Similarly, we repeated all tests with the term structure spread lagged by 3 months, which also did not affect our main conclusions. All suppressed outcomes are available from the authors upon request.

Our evidence suggests that consensus forecasts and term structure spreads both individually forecast real output growth. Interestingly, however, relative explanatory power hinges on the length of the forecast horizon. At short forecast horizons, variation in the consensus forecasts captures approximately one-fifth of the variation in real output growth. These high adjusted $R^{2}$ s decline monotonically to $1.80 \%$ for the longest-term forecast. In contrast, the explanatory power of the term structure spread always clusters around 5\%. Consistent with these findings, the slope coefficient on the term structure spread always attracts significance at the $95 \%$ confidence level, while that on the consensus forecast attracts significance at the same level only for the three shortest horizons. Moreover, when we jointly include the consensus forecast and the term structure spread, we see that the term structure spread contains relevant information in addition to the consensus forecast for the longest-term forecast horizon.

The assumption of quadratic loss might drive the finding that we can reject the rationality of the consensus forecast at the longest-term horizon. To check this possibility, we make use of a methodology proposed by Elliott et al. (2005), which starts from a more general loss function:

$$
L(p, \alpha)=\left[\alpha+(1-2 \alpha) \cdot 1\left(a_{t+q}-f_{t}^{t+q}<0\right)\right]\left|a_{t+q}-f_{t}^{t+q}\right|^{p}
$$

where $\alpha$ controls the asymmetry of the loss function, $p$ is the power to which the forecast error is raised, $a_{t+q}$ is realized economic growth at time $t+q$ and $f_{t}^{t+q}$ is the consensus forecast made at time $t$ for $t+q$. We exogenously set $p$ equal to two. In this case, when $\alpha=0.5$ the stated loss function reduces to the quadratic loss function. Rational forecasters minimize the expectation of equation (2) with respect to the free parameters in $f_{t}^{t+q}$ and set the resulting system of equations equal to zero. Assuming that optimal forecasts are linear in lagged information variables $w_{t}$, this yields

$$
E\left[w_{t}\left(1\left(a_{t+q}-f_{t}^{t+q}<0\right)-\alpha\right)\left|a_{t+q}-f_{t}^{t+q}\right|^{p-1}\right]=0
$$

To test for rationality, Elliott et al. (2005) suggest selecting $\alpha$ so as to minimize a quadratic form of this system of equations and then to use a $J$-test to check whether the equations are jointly significantly different from zero. The $\alpha$ estimator can be considered a special and super-consistent version of a GMM estimator. As asymptotic inferences might be misleading in the case of dependent data, we also compute significance levels from the Hall and Horowitz (1996) GMM block bootstrap.

Table II shows our estimates of $\alpha$ and the $J$-test statistic. Bold numbers are parameter estimates, while the numbers in square brackets and curly brackets are the asymptotic and the block bootstrap $p$-values. In case of the three shorter-term forecasts in panels $\mathrm{A}-\mathrm{C}$, our evidence suggests that forecasters exhibit quadratic loss functions, as $\alpha$ estimates are close to 0.5 and never significantly different from 0.5 . In addition, the $J$-test fails to reject the hypothesis that the moment conditions are jointly different from zero. In the case of the longest-term forecast in panel $\mathrm{D}$, the $\alpha$ estimate is substantially below the former estimates and 0.5 , yet still not significantly different from 0.5 . Nevertheless, in contrast to the traditional rationality tests the $J$-test can no longer reject the rationality of the 1-year-ahead forecast with $\alpha=0.339$.

As a result, if we allow the skewness of agents' loss functions to increase with the forecast horizon, then the term structure spread no longer contains incremental information relevant for forecasting 
Table II. Outcomes of asymmetric rationality test ${ }^{\mathrm{a}}$

\begin{tabular}{|c|c|c|c|c|c|c|}
\hline \# & $\alpha$ & $p(\alpha)$ & Boot $p(\alpha)$ & $J$ & $p(J)$ & Boot $p(J)$ \\
\hline \multicolumn{7}{|c|}{ Panel A: 3-month real $G D(N) P$ growth } \\
\hline 101 & 0.473 & {$[0.74]$} & $\{0.86\}$ & 0.835 & {$[0.66]$} & $\{0.62\}$ \\
\hline \multicolumn{7}{|c|}{ Panel B: 6-month real $G D(N) P$ growth } \\
\hline 100 & 0.442 & {$[0.53]$} & $\{0.75\}$ & 1.217 & {$[0.54]$} & $\{0.49\}$ \\
\hline \multicolumn{7}{|c|}{ Panel $C:$ 9-month real $G D(N) P$ growth } \\
\hline 99 & 0.443 & {$[0.58]$} & $\{0.88\}$ & 0.726 & {$[0.70]$} & $\{0.44\}$ \\
\hline \multicolumn{7}{|c|}{ Panel D: 12-month real $G D(N) P$ growth } \\
\hline 98 & 0.339 & {$[0.14]$} & $\{0.75\}$ & 1.936 & {$[0.38]$} & $\{0.36\}$ \\
\hline
\end{tabular}

${ }^{\text {a }}$ This table shows the estimation outcomes of $\alpha$ and the $J$-test on realized GDP/GNP growth forecast errors, i.e., real $\mathrm{GDP}_{t, t+k}-$ Consensus . We set $p$ equal to two, which implies squared forecast errors. As instruments, we employ a constant and the 1month lagged term structure spread. In addition to the $\alpha$ and $J$-test estimates (bold), we report asymptotic $p$-values and bootstrap $p$-values. The $p$-value associated with $\alpha$ tests the null hypothesis that $\alpha=0.5$, while that associated with the $J$-test checks whether the moment conditions are jointly insignificantly different from zero. The sample period goes from 1981.Q3 to 2006.Q3.

real output growth. The main question in this context is whether it is realistic to assume that agents' loss functions change this substantially over a difference in forecast horizons of only three-quarters. If we are willing to believe this, then our evidence suggests that consensus forecasts are rational. Otherwise, the new methodology, which creates an additional degree of freedom through introduction of $\alpha$, simply lacks power to reject rationality.

\section{CONCLUSION}

We examined whether the consensus forecast of real output growth efficiently embodies information in the term structure spread. We employed revised data as well as the latest vintage data. Apart from the standard methods, we also considered the efficiency of the consensus forecast allowing for the consensus forecast to behave as if generated from an asymmetric loss function. Assuming quadratic loss, our empirical results suggest that the spread does contain information useful for forecasting not reflected in the survey forecast. However, if we allow agents' loss functions to become more negatively skewed with the forecast horizon, we cannot reject the rationality of the forecasts. Nevertheless, an agent who has a quadratic loss function could, in principle, employ the combined forecasts from the standard regressions to improve the predictive content of the survey.

\section{REFERENCES}

Bordo MD, Haubrich JG. 2008. The Yield Curve as a Predictor of Growth: Long-Run Evidence, 1875-1997. Review of Economics and Statistics 90(1): 182-185.

Croushore D. 1993. Introducing: the Survey of Professional Forecasters. Federal Reserve Bank of Philadephia Business Review November: 3-15.

Elliott G, Komunjer I, Timmermann AG. 2005. Estimation and testing of forecast rationality under flexible loss. Review of Economic Studies 72: 1107-1125. 
Estrella A. 1998. Monetary policy and the predictive power of the term structure of interest rates. Federal Reserve Bank of New York.

Estrella A, Hardouvelis G. 1991. The term structure as a predictor of real economic activity. Journal of Finance 46: 555-576.

Estrella A, Mishkin FS. 1998. Financial variables as leading indicators: predicting US recessions. Review of Economics and Statistics 80: 45-61.

Hall P, Horowitz JL. 1996. Bootstrap critical values for tests based on generalized-method-of-moments estimators. Econometrica 64: 891-916.

Kessel RA. 1965. The cyclical behavior of the term structure of interest rates. NBER Occasional Paper 91.

Mitchell WC. 1913. Business Cycles. Princeton University Press: Princeton, NJ.

Mody A, Taylor MP. 2003. The high-yield spread as a predictor of real economic activity: evidence of a financial accelerator for the United States. IMF Staff Papers, 50.

Plosser CI, Rouwenhorst KG. 1994. International term structures and real economic activity. Journal of Monetary Economics 33: 133-155.

Politis DN, Romano JP. 1994. The stationary bootstrap. Journal of the American Statistical Association 89: 1303-1313.

Stark T, Croushore D. 2002. Forecasting with a real-time data set for macroeconomists. Journal of Macroeconomics 24: 507-531.

Authors' biographies:

Kevin Aretz is a Lecturer in Finance. He obtained his Ph.D. in Finance from the University of Lancaster. His research interests focus on theoretical and empirical studies in the fields of asset pricing, forecasting, especially the forecasting of corporate bankruptcy, and corporate finance. His work has been published in several international economics and finance journals, including the Journal of Financial Research.

David A. Peel is a Professor in Economics. He was educated at University of Warwick. Professor Peel has published widely on empirical and theoretical issues in macroeconomics and the economics of gambling markets. He has published pioneering papers in the application of nonlinear-ESTAR models to purchasing power parity deviations, the political theory of the business cycle, uncertainty and football attendance, central banks with asymmetric preferences and political popularity series modelled as fractional processes.

Authors' addresses:

Kevin Aretz, Department of Accounting and Finance, Lancaster University, Lancaster LA1 4YX, UK.

David A. Peel, Department of Economics, Lancaster University, Lancaster LA1, 4YX, UK. 